\title{
A Molecular Platform in Neurons Regulates Inflammation after Spinal Cord Injury
}

\author{
Juan Pablo de Rivero Vaccari, ${ }^{1}$ George Lotocki, ${ }^{2}$ Alex E. Marcillo, ${ }^{2}$ W. Dalton Dietrich, ${ }^{2}$ and Robert W. Keane ${ }^{1}$ \\ ${ }^{1}$ Department of Physiology and Biophysics and ${ }^{2}$ Neurological Surgery and Miami Project to Cure Paralysis, Miller School of Medicine, University of Miami, \\ Miami, Florida 33136
}

\begin{abstract}
Vigorous immune responses are induced in the immune privileged CNS by injury and disease, but the molecular mechanisms regulating innate immunity in the CNS are poorly defined. The inflammatory response initiated by spinal cord injury (SCI) involves activation of interleukin-1 $\beta$ (IL-1 $\beta$ ) that contributes to secondary cell death. In the peripheral immune response, the inflammasome activates caspase-1 to process proinflammatory cytokines, but the regulation of trauma-induced inflammation in the CNS is not clearly understood. Here we show that a molecular platform [NALP1 (NAcht leucine-rich-repeat protein 1) inflammasome] consisting of caspase-1, caspase-11, ASC (apoptosis-associated speck-like protein containing a caspase-activating recruitment domain), and NALP1 is expressed in neurons of the normal rat spinal cord and forms a protein assembly with the X-linked inhibitor of apoptosis protein (XIAP). Moderate cervical contusive SCI induced processing of IL-1 $\beta$, IL-18, activation of caspase-1, cleavage of XIAP, and promoted assembly of the multiprotein complex. Anti-ASC neutralizing antibodies administered to injured rats entered spinal cord neurons via a mechanism that was sensitive to carbenoxolone. Therapeutic neutralization of ASC reduced caspase-1 activation, XIAP cleavage, and interleukin processing, resulting in significant tissue sparing and functional improvement. Thus, rat spinal cord neurons contain a caspase-1, pro-IL $\beta$, and pro-IL-18 activating complex different from the human NALP1 inflammasome that constitutes an important arm of the innate CNS inflammatory response after SCI.
\end{abstract}

Key words: spinal cord injury; inflammasome; interleukins; caspases; cytokines; inflammation

\section{Introduction}

Spinal cord injury (SCI) is a complex and devastating condition mediated by proinflammatory cytokines that produces the secondary injury cascade (Dusart and Schwab, 1994; Bartholdi and Schwab, 1997; Bethea, 2000; Carmel et al., 2001; Bethea and Dietrich, 2002; Bareyre and Schwab, 2003; Norenberg et al., 2004). Increased production of cytokines of the interleukin-1 (IL-1) family, such as IL-1 $\beta$, is well documented, providing clear evidence for a pivotal role of this cytokine in triggering SCI-induced inflammatory processes (Benveniste, 1992; Dusart and Schwab, 1994; Kuida et al., 1995; Bhat et al., 1996; Popovich et al., 1997, 2001, 2002; Schnell et al., 1999b; Bethea, 2000; Carmel et al., 2001; Pearse et al., 2004). IL-1 $\beta$ and IL-18 are potent mediators of inflammation and initiate and/or amplify a wide variety of effects associated with innate immunity, host responses to tissue injury, and microbial invasion (Bhat et al., 1996; Dinarello, 2005, 2006). Although many important biological effects of IL- $1 \beta$ and IL-18 have been described, key questions remain unresolved about the

Received Nov. 12, 2007; accepted Feb. 16, 2008.

This work was supported by grants from National Institutes of Health/National Institute of Neurological Disorders and Stroke and the United States Army battlefield exercise and combat-related spinal cord injury research and development. We thank Andrew Sawaya, Enrique R. Perez, and David Molnar for technical assistance.

Correspondence should be addressed to Robert W. Keane, Department of Physiology and Biophysics, Miller School of Medicine, University of Miami, 1600 NW 10th Avenue, Miami, FL 33136. E-mail: rkeane@miami.edu. DOI:10.1523/JNEUROSCI.0157-08.2008

Copyright $\odot 2008$ Society for Neuroscience $\quad$ 0270-6474/08/283404-11\$15.00/0 mechanisms by which the production of these cytokines is regulated, particularly in the CNS.

Both IL-1 $\beta$ and IL-18 are synthesized as inactive cytoplasmic precursors that are proteolytically processed as biologically active forms in response to proinflammatory stimuli by caspase- 1 , a cysteine protease (Burns et al., 2003; Martinon and Tschopp, 2004; Dinarello, 2005). The processing of pro-IL-1 $\beta$ involves the activation of a multiprotein caspase-1-activating complex termed the inflammasome (Martinon et al., 2002; Martinon and Tschopp, 2007; Ogura et al., 2006). The inflammasome in humans is formed by members of the NAcht leucine-rich-repeat proteins (NALP) protein family, such as NALP1, NALP2, or NALP3, and the adaptor protein apoptosis-associated speck-like protein containing a caspase-activating recruitment domain (CARD) (ASC) that connects the NALPs with caspase-1 (Tschopp et al., 2003; Agostini et al., 2004). However, the molecular composition of inflammasomes in the rat has not yet been determined. Activation of the inflammasome results in processing and secretion of proinflammatory IL- $1 \beta$ and IL- 18 , thus triggering the inflammatory response (Martinon et al., 2002; Martinon and Tschopp, 2004; Miao et al., 2006; Ozoren et al., 2006). Inflammasome components show a distinct and nonoverlapping tissue distribution (Kummer et al., 2007), suggesting different roles in separate cell types, but the signals and mechanisms leading to inflammasome activation, particularly in the CNS, remain poorly defined. Moreover, it has been speculated that the inflammasome is kept in an inactive state in normal 
tissues by binding to a putative caspase-1 inhibitor, but the nature of this inhibitor has not been described (Dinarello, 2005). Here we show that a molecular platform (NALP1 inflammasome) consisting of NALP1, ASC, caspase-1, and caspase-11 is present in neurons of the normal rat spinal cord and forms a protein assembly with the inhibitor of apoptosis family member, $\mathrm{X}$-linked inhibitor of apoptosis protein (XIAP). SCI induced rapid processing of IL- $1 \beta$ and IL-18, activation of caspase-1, cleavage of XIAP, and promoted assembly of the NALP1 inflammasome. Moreover, neutralization of ASC reduced caspase- 1 activation and XIAP cleavage and decreased processing of IL- $1 \beta$ and IL-18, leading to improved histopathological and functional outcomes after SCI.

\section{Materials and Methods}

Animals and spinal cord injury. Adult female Fischer (180-200 g) rats were used in these studies. All animal procedures were approved by the Institutional Animal Care and Use Committee of the University of Miami. Rats were anesthetized with ketamine $(87 \mathrm{mg} / \mathrm{kg})$ and xylazine $(13$ $\mathrm{mg} / \mathrm{kg}$ ). Adequate amounts of anesthesia were determined by monitoring toe touch. Using aseptic techniques, a midline incision was made in the neck in the skin and musculature to expose the C2-T1 vertebrae. A laminectomy was performed at vertebral level C5 exposing the cord. A moderate contusion injury ( $2000 \mathrm{kdyn}$ of force) was induced by displacing the spinal cord $0.95 \mathrm{~mm}$ using the circular flap tip of the impactor of the Electromagnetic SCI Device (Ohio State University, Columbus, $\mathrm{OH}$ ). Body and spinal cord temperature were maintained at $37.5^{\circ} \mathrm{C}$ with a feedback-controlled heating blanket, which was monitored by a rectal thermometer. After injury, the incision was closed with wound clips and sutures, and each rat was returned to its cage. Animals were killed at different times after SCI. Sham animals were used as controls.

Antibodies. Rabbit anti-Rattus novegicus ASC and NALP1 antisera were prepared by Bethyl Laboratories (Montgomery, TX) based on protein sequences (ASC: ALR QTQ PYL VTD LEQ S; NALP1: MEE SQS KEE SNT EG-cys) obtained from the National Center For Biotechnology Information website: accession numbers XP-340836 for NALP1 and BAC43754 for ASC. Other antibodies were purchased from commercial sources and include the following: anti-NALP1 (Abcam, Cambridge, MA), anti-IL-1 $\beta$ (Cell Signaling Technology, Beverly, MA), anti-IL-18 (R \& D Systems, Minneapolis, MN), anti-caspase-1 (Millipore, Billerica, MA), anti-caspase-1 (Santa Cruz Biotechnology, Santa Cruz, CA), anticaspase-11 (Alexis Biochemicals, San Diego, CA), anti-caspase-11 (Santa Cruz Biotechnology), anti-XIAP (BD Transduction Laboratories, Lexington, KY); anti-caspase-3 (Millipore), anti-microtubule associated protein-2 (MAP2) (Millipore Bioscience Research Reagents, Temecula, CA), anti-adenomatous polyposis coli (APC) (Millipore Bioscience Research Reagents), anti-glial fibrillary acidic protein (GFAP) (Millipore Bioscience Research Reagents), anti-CD11b (Millipore Bioscience Research Reagents), fluorescein isothiocyanate (FITC)-conjugated antiactin (Sigma, St. Louis, MO), and Alexa Fluor 488-conjugated rabbit IgG (Invitrogen, Carlsbad, CA).

Spinal cord neuronal cultures. Neuronal cultures were prepared from embryonic day 14 (E14) to E15 rat embryo spinal cords as described previously (Tedeschi et al., 1986; Keane et al., 1992). Spinal cord tissue was disrupted into a cell suspension by gentle trituration, and the cells were grown on poly-L-lysine-coated tissue culture dishes in N5 medium that contained 5\% serum fraction (Kawamoto and Barrett, 1986). The neuronal nature of the majority of cells (95\%) was confirmed electrophysiologically and immunohistochemically (Tedeschi et al., 1986). Cultures were grown for $14 \mathrm{~d}$ and then treated with $1.0 \mu \mathrm{M}$ valinomycin (Sigma) for $4 \mathrm{~h}$, and controls were left untreated. Cells were washed once in ice-cold PBS and lysed as described previously (Keane et al., 1997). Supernatants were harvested and analyzed for IL- $1 \beta$ levels by ELISA (R \& D Systems).

Antibody uptake by spinal cord neurons. To investigate the mechanism by which spinal cord neuron uptake anti-ASC, spinal cord neurons were grown in culture for $7 \mathrm{~d}$ at a density of $2 \times 10^{6}$ per $60 \mathrm{~mm}$ tissue culture
A

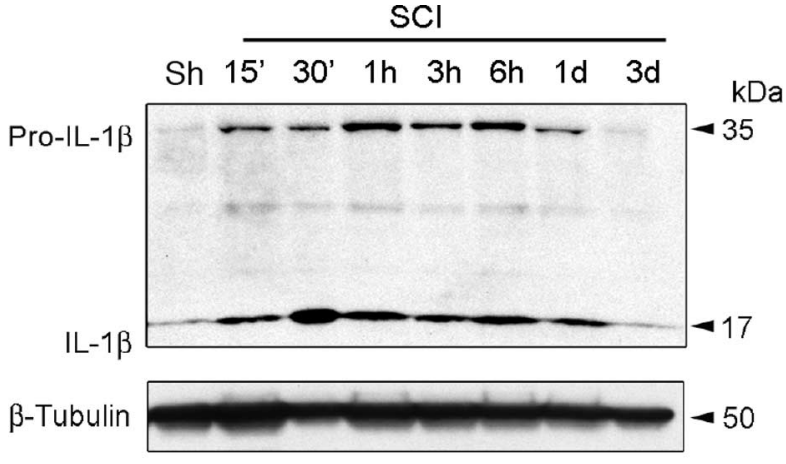

B $\mathrm{SCl}$

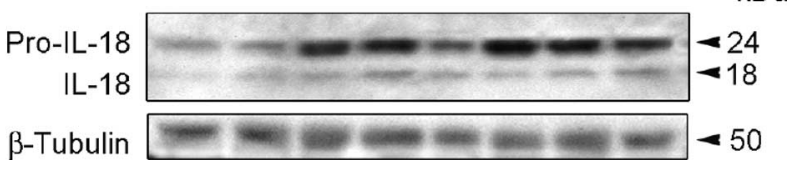

Figure 1. SCl induces processing of IL-1 $\beta$ and IL-18 early after injury. Representative immunoblot analysis of spinal cord lysates of sham animals ( $\mathrm{Sh}$ ) and traumatized rat cords at $15 \mathrm{~min}$, 30 min, $1 \mathrm{~h}, 3 \mathrm{~h}, 6 \mathrm{~h}, 1 \mathrm{~d}$, and $3 \mathrm{~d}$ after injury. $\boldsymbol{A}, \boldsymbol{B}$, Spinal cord lysates were immunoblotted with antibodies against IL-1 $\beta(\boldsymbol{A})$ and IL-18(B). $\beta$-Tubulin was used as internal standard and control for protein loading.

dish and treated for $1 \mathrm{~h}$ with anti-ASC $(5 \mu \mathrm{g})$ that was conjugated to FITC using the EZ-Label FITC Protein Labeling kit (Thermos) according to the instructions of the manufacturer. Other cultures were pretreated for 30 min with $10 \mathrm{~mm}$ cytochalasin D to block endocytosis or with $100 \mu \mathrm{m}$ carbenoxolone, a nonspecific pannexin inhibitor before addition of FITC-anti-ASC, FITC-actin, or FITC-rabbit IgG alone. After $1 \mathrm{~h}$ incubation, neurons were washed twice in Dulbecco's PBS, fixed with $10 \%$ buffered Formalin and examined with a Nikon (Tokyo, Japan) eclipse E600 fluorescent microscope.

Immunoblotting. Three to $4 \mathrm{~mm}$ segments of sham or injured spinal cords were homogenized in PTN50 extraction buffer (50 mM NaPi, pH $7.4,50 \mathrm{~mm} \mathrm{NaCl}$, and $1 \%$ Triton X-100) with proteases $(1 \mu \mathrm{g} / \mathrm{ml}$ pepstatin A, $1 \mu \mathrm{M}$ aprotinin, $1 \mathrm{~mm}$ phenylmethylsulfonyl fluoride, and $5 \mu \mathrm{g} / \mathrm{ml}$ leupeptin). Proteins were resolved in $10-20 \%$ Tris- $\mathrm{HCl}$ Criterion precasted gels (Bio-Rad, Hercules, CA), transferred to polyvinylidene difluoride membranes (Applied Biosystems, Foster City, CA), placed in blocking buffer [PBS, $0.1 \%$ Tween 20, and 0.4\% I-Block (Applied Biosystems)], and then incubated for $1 \mathrm{~h}$ with the following: monoclonal antibody to caspase-11 (1:1000; Alexis Biochemicals), monoclonal antibody to caspase-1 (1:1000; Millipore), rabbit anti-Rattus novegicus, affinity-purified antibody ASC (1:10,000; Bethyl Laboratories), NALP1 (1:5000; Bethyl Laboratories), and NALP1 (1:1000; Abcam). Membranes were incubated for $1 \mathrm{~h}$ with primary antibodies followed by appropriate secondary horseradish peroxidase (HRP)-linked antibodies (Cell Signaling Technology). Visualization of signal was enhanced by chemiluminescence using a phototope-HRP detection kit (Cell Signaling Technology). To control for protein loading, immunoblots were stripped with Restore, Western blot stripping buffer (Pierce, Rockford, IL), and blotted for $\beta$-tubulin using monoclonal anti- $\beta$-tubulin antibody (1:5000; BD Biosciences PharMingen, San Diego, CA). Quantification of band density was performed using the NIH ImageJ $1.34 \mathrm{~s}$ software, and data were normalized to $\beta$-tubulin.

Coimmunoprecipitation. To assess the protein composition and association of proteins in the inflammasome, $500 \mu \mathrm{g}$ of spinal cord lysates from uninjured animals and traumatized animals at $30 \mathrm{~min}, 6 \mathrm{~h}$, and $3 \mathrm{~d}$ were immunoprecipitated with anti-ASC or anti-NALP1 antibodies using TrueBlot anti-rabbit Ig immunoprecipitation beads. Spinal cord lysates were precleared by adding $50 \mu \mathrm{l}$ of anti-rabbit TrueBlot beads to 500 $\mu \mathrm{g}$ of lysate in a microcentrifuge tube. The mixture was incubated for $1 \mathrm{~h}$ at $4^{\circ} \mathrm{C}$, and beads were pelleted by centrifugation at $12,000 \times g$ for $30 \mathrm{~s}$. 
The supernatant was recovered and immunoprecipitated with $5 \mu \mathrm{g}$ of anti-ASC or antiNALP1 and incubated at $4^{\circ} \mathrm{C}$ overnight. Fifty microliters of anti-rabbit TrueBlot beads were added to the mixture, incubated for $2 \mathrm{~h}$, and then centrifuged at $12,000 \times g$ for $30 \mathrm{~s}$. The pelleted beads were washed five times in lysis buffer, resuspended in loading buffer, and heated at $95^{\circ} \mathrm{C}$ for $3 \mathrm{~min}$ before analysis by immunoblotting using antibodies against ASC, NALP1, capase-11 and caspase-1, caspase-3, and XIAP. Controls using preimmune antiserum and a control reverse coimmunoprecipitation using anti-NALP1 were run in parallel. Anti-ASC and anti-NALP1 antibody specificity was evaluated by preabsorption of antiserum with immunogen peptides to remove specific antibody binding. Immunogen depleted antiserum was then used as a negative control for immunoblotting procedures.

Perfusion fixation. Animals were anesthetized with ketamine $(87 \mathrm{mg} / \mathrm{kg})$ and xylazine $(13 \mathrm{mg} /$ $\mathrm{kg}$ ) and perfused with $500 \mathrm{ml}$ of $4 \%$ paraformaldehyde. Spinal cords were removed and placed in $4 \%$ paraformaldehyde at $4^{\circ} \mathrm{C}$ for $20 \mathrm{~h}$. Then cords were transferred to $20 \%$ sucrose in $0.1 \mathrm{~m}$ PBS and stored at $4^{\circ} \mathrm{C}$ until sectioning.

Immunohistochemistry. Immunostained spinal cord sections of uninjured and injured rats at $6 \mathrm{~h}$ were examined with a Zeiss (Jena, Germany) laser scanning confocal microscope (Zeiss). Rats were perfused with $4 \%$ paraformaldehyde as described and processed for cryostat sectioning (Leica SM 2000R Sliding Microtome). Sections $(50 \mu \mathrm{m})$ were blocked by treatment with normal goat serum (Vector Laboratories, Burlingame, CA). Tissue sections were rinsed with $0.1 \mathrm{M}$ PBS, $\mathrm{pH} 7.4$, and incubated overnight at $4{ }^{\circ} \mathrm{C}$ with primary antibodies against caspase-1 (1:500), caspase-11 (1:500), ASC (1:500), and NALP1 (1:500). To determine the precise cellular distribution of inflammasome proteins, sections were double stained with cell-type-specific markers: mouse antineuronal nuclei (neurons; Millipore Bioscience Research Reagents); mouse anti-MAP2 (neurons; Millipore Bioscience Research Reagents); mouse anti-APC (oligodendrocytes; Calbiochem, San Diego, CA); mouse anti-rat CD11b (microglia; Millipore Bioscience Research Reagents); and mouse antiGFAP (astrocytes; Millipore Bioscience Research Reagents). AlexaFluor secondary antibody conjugates (Invitrogen) were used as secondary antibodies. Controls using an irrelevant antibody of the same isotype were run in parallel to evaluate antibody specificity. In addition, anti-ASC and anti-NALP1 antibody specificity was evaluated by preabsorption of antisera with immunogen peptides to remove specific antibody binding. Immunogen depleted antisera were then used as a negative control for immunostaining procedures. Sections were coverslipped with Vectashield mounting medium (Vector Laboratories) and analyzed with a Zeiss LSM510 laser scanning confocal microscope.

ASC neutralization. Female Fischer rats were subjected to moderate cervical SCI. For inflammasome inhibition, anti-ASC antibody $(50 \mu \mathrm{g})$ was injected intravenously and intraperitoneally $20 \mathrm{~min}$ after SCI. Controls were treated with an equal amount of IgG and saline or were left untreated. After $24 \mathrm{~h}$, animals were anesthetized with ketamine $(87 \mathrm{mg} /$ $\mathrm{kg})$ and xylazine $(13 \mathrm{mg} / \mathrm{kg})$ and killed. The spinal cord was immediately removed, frozen in liquid nitrogen, and preserved in a freezer at $-80^{\circ} \mathrm{C}$ until analysis by immunoblotting. For lesion volume analysis, animals
B
SCI

$\mathrm{kDa}$

(1)

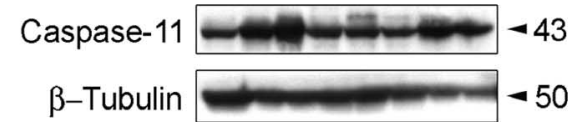

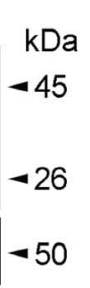

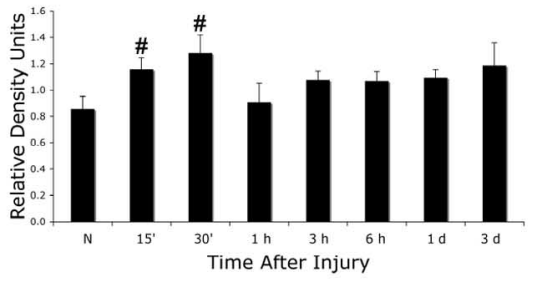

D

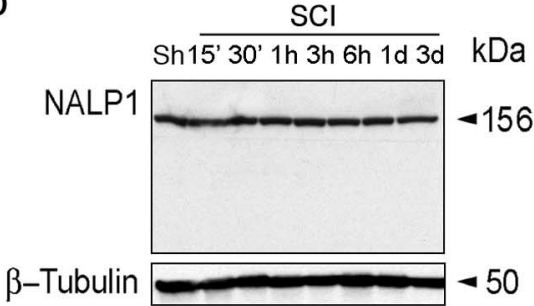

Figure 2. SCl induces activation and processing of caspase- 1 and increases levels of ASC and caspase- 11 but not NALP1. A-D , and traumatized rat cords at indicated times after injury. $\boldsymbol{C}$ shows that anti-ASC reacts specifically with ASC (26 kDa) and nonspecifically with proteins of $\sim 49$ and $55 \mathrm{kDa}$ (arrows, left). $\beta$-Tubulin was used as internal standard and control for protein

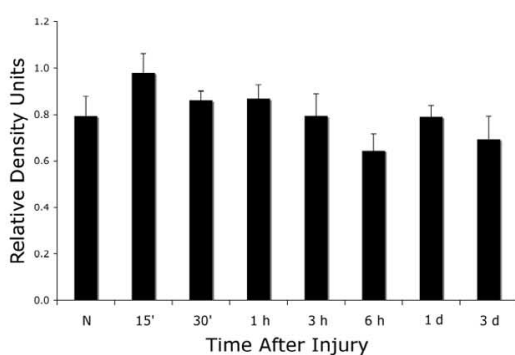


assisted microscopy and Neurolucida software (MicroBrightField, Colchester, VT). In each section, the total area of the 10-mm-long cord segment was first determined. Damaged white and gray matter areas were determined. Tissue was characterized as damaged by the presence of infiltrating immune cells, myelin breakdown, shrunken eosinophilic neurons, and hemorrhage. The areas of each section was calculated by Neurolucida software and then summated for the volumes of each spinal cord.

Behavioral testing. A battery of tasks that have been proven useful in assessing functional outcome after cervical SCI were used (Pearse et al., 2005). These tests include the forelimb gripping strength test, the sticker removal test, and footprint analysis.

Forelimb gripping strength test. To measure forelimb strength at 2 weeks after SCI, animals were gently held and permitted to grasp with their forelimbs a mesh grip connected to a digital force gauge (San Diego Instruments, San Diego, CA). The animal was then drawn along a straight line leading away from the sensor until the animal released the mesh. The maximum grip strength was maintained and displayed (in newtons) as the gripping force. The average reading of three successive trials was recorded for each animal.

Sticker removal test. Deficits in motor skills were examined by assessing the ability of rats to remove a sticker ( 1.0 inch diameter) that was placed in the bridge of their nose. A six-point rating scale was used to determine motor control (Diener and Bregman, 1998). Animals were allowed 2 min to remove the sticker and received a score of 1-6 based on the following criteria: (1) animal did not attempt to remove the sticker; (2) animal attempted to remove the sticker but their forelimbs did not reach the sticker; (3) animal forelimbs reached the sticker after the head was contracted, but the sticker was not removed; (4) animal forelimbs reached the sticker without head contraction, but the sticker was not removed; (5) animal removed the sticker after several attempts; and (6) animals removed the sticker with no difficulty on the first attempt.

Footprint analysis. At 7 weeks after SCI, footprint analysis was used to quantify the ability of injured rats to maintain quadrupedal stance using the protocol of de Medinaceli et al. (1982) with slight modifications. The animal's forepaws and hindpaws were inked with different colors, and the animal was allowed to walk on a strip of paper covering a narrow runway measuring $1 \mathrm{~m}$ in length and $7 \mathrm{~cm}$ in width. A series of eight sequential steps was used to determine the mean values of stride length, foot rotation, and base of support. Base of support was determined by measuring the core-to-core distance of the central pads of the forepaws. Stride length corresponded to the distance between consecutive steps with the forelimbs on each side. Foot rotation was defined by the angle formed by the third digit and the line through the central pad parallel to the walking direction.

Statistical analysis. Data are expressed as \pm SEM. Statistical comparisons between uninjured and injured groups were made using two-tailed Student's $t$ test and a one-way ANOVA followed by Tukey's multiple comparison tests. $p$ values of significance used were ${ }^{\star} p<0.05$ and ${ }^{\#} p<$ 0.10 .

\section{Results}

\section{SCI induces processing of IL-1 $\beta$ and IL-18}

Excessive levels of the proinflammatory cytokines IL- $1 \beta$ and IL-18 are associated with secondary damage after SCI (Schnell et al., 1999b). To determine whether SCI induced processing of proinflammatory cytokines, we analyzed spinal cord lysates from injured and sham-operated animals for IL- $1 \beta$ and IL-18. Increased levels of pro-IL-1 $\beta$ (Fig. $1 A$ ) and pro-IL-18 (Fig. $1 B$ ) were present in spinal cord lysates within 15-30 min after injury. However, the time course of maturation of these inflammatory cytokines differed. Levels of IL- $1 \beta$ continued to rise early after injury but decreased by 1 and $3 \mathrm{~d}$ after trauma. In contrast, levels of processed IL-18 increased early after SCI, decreased by $3 \mathrm{~h}$, and then continued to rise by 1 and $3 \mathrm{~d}$. Thus, SCI induces an inflammatory cascade consisting of production of pro-IL- $1 \beta$ and proIL-18 and processing of these precursors into mature inflammatory cytokines.

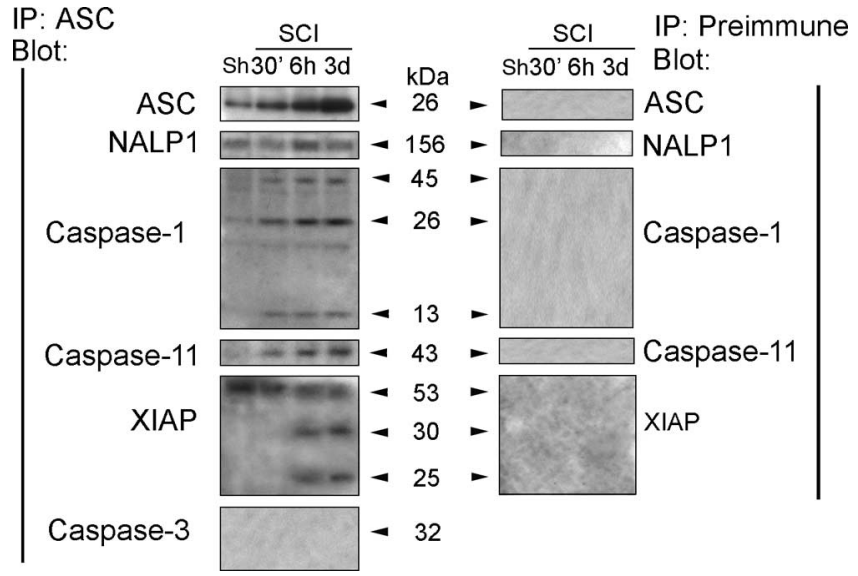

Figure 3. $\mathrm{SCl}$ induces association of NALP1 inflammasome proteins, processing of caspase-1, and cleavage of XIAP. Coimmunoprecipitation with ASC of sham lysates (Sh) and lysates obtained at $30 \mathrm{~min}, 6 \mathrm{~h}$, and $3 \mathrm{~d}$ after SCI. ASC immunoprecipitates were blotted for ASC, caspase-1, caspase-11, NALP1, XIAP, and caspase-3 (control). In sham animals, anti-ASC immunoprecipitated (IP) NALP1, caspase-1, caspase-11, and the $53 \mathrm{kDa}$ XIAP, thus indicating association of these proteins in a multiprotein complex. SCl induced increased association of NALP1 inflammasome proteins, processing of caspase-1 and caspase-11, and cleavage of XIAP into fragments. Preimmune serum did not immunoprecipitate inflammasome proteins and was used as control.

\section{SCI induces expression of inflammasome proteins}

Processing of pro-IL- $1 \beta$ and IL-18 involves the activation of a caspase-1-activating platform, termed the inflammasome (Martinon et al., 2002; Ogura et al., 2006; Martinon and Tschopp, 2007). To provide direct evidence for involvement of the inflammasome in SCI-induced inflammation, we analyzed traumatized spinal cords for the time course of expression of key inflammatory caspases and inflammasome proteins (Fig. 2). SCI rapidly activated caspase-1 (Fig. 2A) and upregulated caspase-11, the rodent ortholog of human caspase-5 (Fig. 2B). Proteolytic processing of procaspase- 1 was detected at 15 min after trauma. Accordingly, there were significant increases in the levels of the adaptor protein ASC within $1 \mathrm{~h}$ after SCI (Fig. 2C), whereas no significant changes in the levels of NALP1 were observed (Fig. $2 D)$. NALP3 was not detected in lysates from sham and traumatized animals at any time point examined (data not shown) and served as a control. These results demonstrate that SCI rapidly stimulates expression of inflammasome signaling molecules, suggesting a possible involvement of the inflammasome in the initiation of the inflammatory response after SCI.

\section{SCI induces dramatic changes in the composition of the inflammasome multiprotein complex}

In humans, three types of inflammasomes have been proposed based on biochemical analysis of three apoptosis proteaseactivating factor (Apaf)-like proteins, NALP1, NALP2/3, and Iceprotease activating factor (Ipaf) (Tschopp et al., 2003; Agostini et al., 2004; Dinarello, 2004b). However, the protein composition of inflammasomes in the rat has not yet been established. To characterize associations of inflammasome proteins after SCI, coimmunoprecipitations of spinal cord lysates from sham (uninjured) rats, and lysates at various time points after injury were performed using anti-ASC antibody (Fig. 3). In sham spinal cords, ASC was immunoprecipitated with anti-ASC; however, very low levels of caspase- 1 and caspase- 11 were present in this signaling complex. NALP1 was associated with ASC in sham spinal cords, whereas high levels of full-length XIAP were present in the mul- 
tiprotein complex (Fig. 3). At 30 min after $\mathrm{SCI}$, the composition of the signaling complex changed. Notably, there was increased association of caspase- 1 and caspase-11 with ASC, but the levels of NALP1 associated with ASC remained constant. However, the levels of full-length XIAP in the molecular platform decreased. The cleaved p26 and p13 subunits of caspase-1 were generated at $30 \mathrm{~min}$ after SCI. At $6 \mathrm{~h}$ and $3 \mathrm{~d}$ after trauma, the full-length $53 \mathrm{kDa}$ XIAP protein was cleaved to generate 25 and 30 $\mathrm{kDa}$ fragments. Anti-ASC did not immunoprecipitate caspase-3 (Fig. 3), whereas preimmune serum did not immunoprecipitate the inflammasome-associated proteins (Fig. 3), demonstrating antibody specificity and thus serving as controls. In reciprocal coimmunoprecipitation experiments, anti-NALP1 immunoprecipitated ASC, caspase-1, and caspase-11, as well as XIAP, but it did not immunoprecipitate caspase-3, thus providing additional evidence for formation of the inflammasome complex after SCI (supplemental Fig. S1, available at www.jneurosci.org as supplemental material). These findings suggest that SCI activates a molecular platform (termed the NALP1 inflammasome) that consists of ASC, caspase-1, caspase-11, NALP1, and XIAP, leading to activation of caspase- 1 and cleavage of XIAP.

Inflammasome proteins are present in spinal cord neurons, and SCI induces alterations in protein expression pattern Figure 4 shows confocal images of the cell type expression and regional distribution of NALP1 inflammasome proteins in motor neurons in the ventral horn of sham and injured spinal cords at $6 \mathrm{~h}$ after injury. Sections were stained for caspase-1, caspase-11, ASC, and NALP1 (red) and the neuronal marker MAP2 (green). Caspase-1 immunoreactivity was seen in MAP2positive cells, indicating that caspase- 1 is expressed in neurons in the spinal cord of sham animals. Intense caspase- 1 immunoreactivity was seen in the nucleus (arrow), and patchy staining was present in the cell cytoplasm (arrow) and processes. In contrast, caspase-11 immunoreactivity demonstrated diffuse punctate staining confined to the neuronal soma and processes. Intense ASC and NALP1 staining was detected in the soma of spinal cord neurons and exhibited a patchy distribution pattern (arrows), whereas weak NALP1 immunoreactivity was detected in the nucleus. Astrocytes, oligodendrocytes, and microglia expressed ASC but did not express NALP1, suggesting that ASC may serve as an adaptor for the enhancement of other inflammasome complexes (NALP2/3) in glial cells (supplemental Table S1).

Moderate cervical SCI resulted in altered staining patterns of
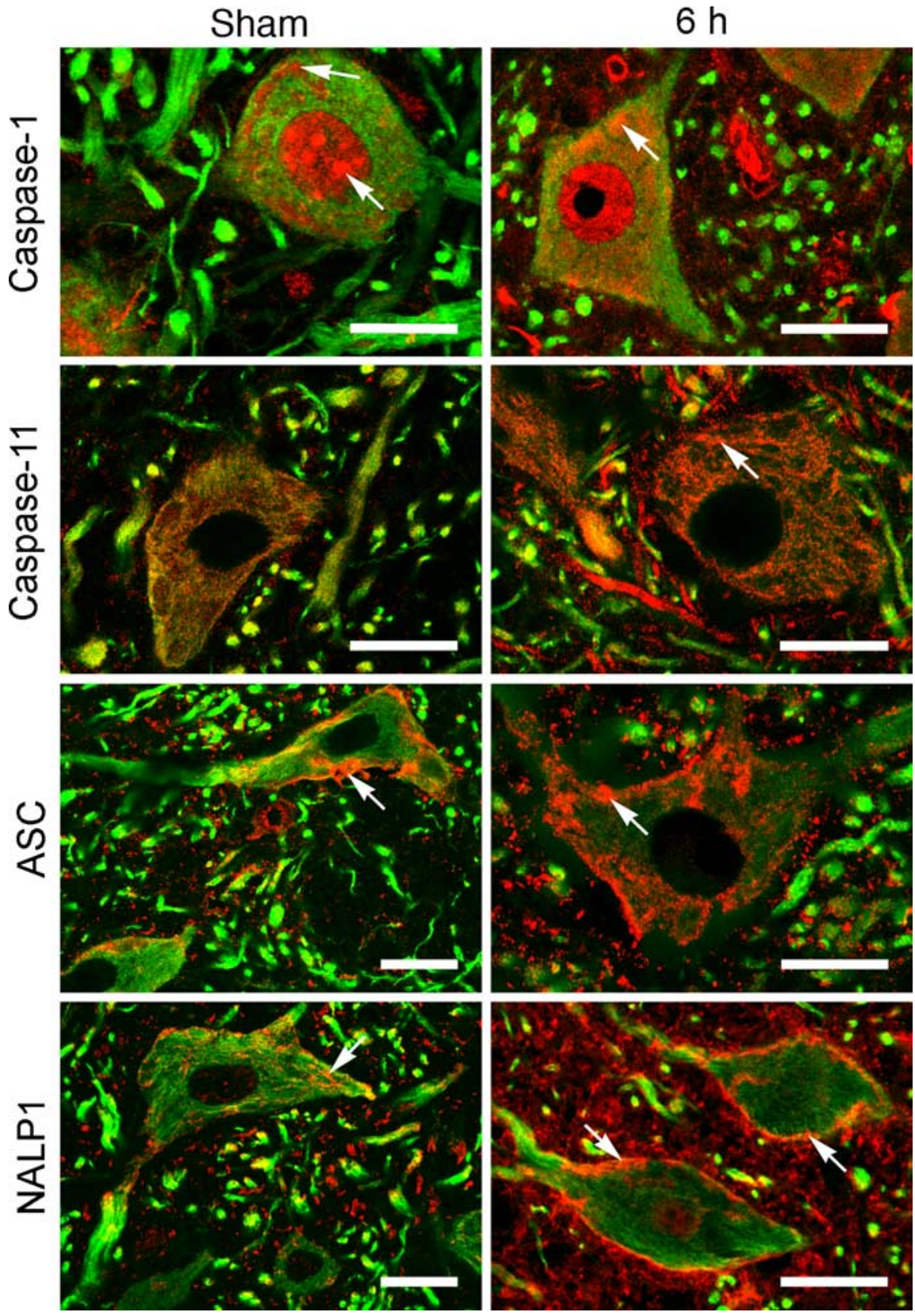

Figure 4. NALP1 inflammasome proteins are present in spinal cord motor neurons, and SCl induces alterations in protein expression patterns. Confocal images show motor neurons in the ventral horn of sham and injured spinal cords at $6 \mathrm{~h}$ after trauma. Sections were stained for caspase-1, caspase-11, ASC, and NALP1 (red) and the neuronal marker MAP2 (green). In sham animals, caspase- 1 immunoreactivity was seen in the nucleus (arrow). By $6 \mathrm{~h}$ after injury, increased caspase-1 staining was present in neuronal nuclei, and patchy staining was present in the cell cytoplasm (arrow) and processes near the plasma membrane. Caspase-11 immunoreactivity showed diffuse punctate staining confined to the neuronal soma and processes (arrow). Increased caspase-11 staining was present by $6 \mathrm{~h}$ after trauma in the neuronal soma in a patchy distribution (arrow). Intense ASC and NALP1 staining was detected in the soma of spinal cord neurons and exhibited a patchy distribution pattern in the cytoplasm (arrow). Both inflammasome proteins showed increased expression as evidenced by intense patchy staining located near or associated with the plasma membrane (arrows) by $6 \mathrm{~h}$ after trauma. Scale bars, $20 \mu \mathrm{m}$. inflammasome proteins in spinal cord neurons (Fig. 4). At $6 \mathrm{~h}$ after injury, increased caspase- 1 immunoreactivity was present in neuronal nuclei, whereas intense caspase-1 staining was seen in the cell cytoplasm as large patches (arrow) near the plasma membrane. Increased caspase-11 staining was present in the neuronal soma that was localized in a patchy distribution (arrow). A more striking alteration was observed in the immunostaining of ASC and NALP1 after SCI. By $6 \mathrm{~h}$ after SCI, immunoreactivity of both 


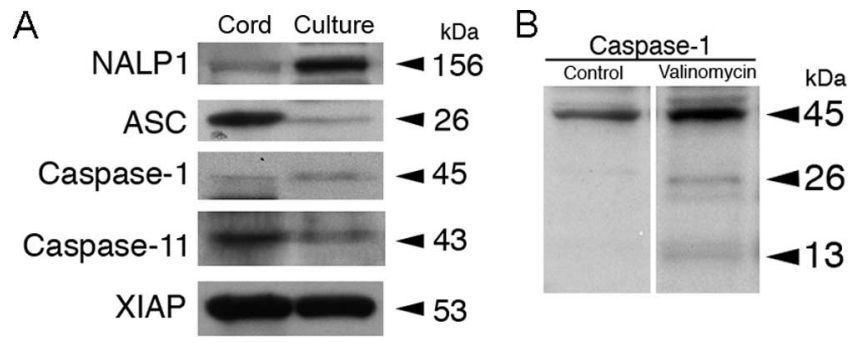

Figure 5. A, NALP1 inflammasome proteins are expressed in spinal cord neurons in culture. Spinal cord neurons ( $~ 95 \%$ pure) were grown in culture for $14 \mathrm{~d}$, harvested, and lysed. A segment (C5-C7) of adult rat spinal cord was excised and homogenized as outlined in Materials and Methods. Samples were immunoblotted for NALP1, ASC, caspase-1, caspase-11, and XIAP. Neurons in culture (culture); spinal cord tissue (cord). $\boldsymbol{B}$, Activation of caspase-1 is induced in spinal cord neurons by treatment with the $\mathrm{K}^{+}$ionophore valinomycin. Spinal cord neuronal cultures were grown for $14 \mathrm{~d}$ and treated for $4 \mathrm{~h}$ with $1 \mu \mathrm{m}$ valinomycin or were left untreated (control). The cells were lysed and analyzed by immunoblot for caspase-1.

inflammasome proteins was markedly enhanced, and intense patchy staining was seen in the neuronal soma near or associated with the plasma membrane (arrows). As shown previously, XIAP was present in the perinuclear region and cell processes of spinal cord neurons and SCI induced alterations in the expression pattern (Keane et al., 2001). The cellular distribution and location of NALP1 inflammasome proteins near the plasma membrane of neurons after SCI is consistent with their role in the processing and secretion of IL- $1 \beta$. Anti-ASC and anti-NALP1 antibody specificity was evaluated by preabsorption of antiserum with immunogen peptides to remove specific antibody binding. Immunopeptide depleted antiserum did not stain sections of sham and traumatized spinal cords and served as a negative control (supplemental Fig. S2, available at www.jneurosci.org as supplemental material). Of importance is the fact that the intensity and pattern of inflammasome protein expression in neurons was strikingly altered by SCI and is consistent with the idea that neurons process and secrete IL- $1 \beta$ and IL-18 via activation of the inflammasome complex.

To further confirm that inflammasome proteins formed protein/ protein interactions in neurons, triple-immunohistochemical labeling was performed followed by confocal microscopy. As shown in supplemental Fig. S3A (available at www.jneurosci.org as supplemental material) caspase-1 (red), ASC (green), and NALP1 (blue) were present in motor neurons of the spinal cord and demonstrated overlapping expression patterns (white) as evidenced in the profile analysis. Similar overlapping staining patterns (white) were observed in sections stained with caspase-11 (red), ASC (green), and XIAP (blue) (supplemental Fig. 3B, available at www.jneurosci.org as supplemental material), supporting the idea that caspase-1, caspase-11, ASC, NALP1, and XIAP form a multiprotein complex within the cytoplasm of motor neurons of the spinal cord. These immunohistochemical studies support coimmunoprecipitation experiments that show protein/protein interactions among ASC/ caspase-1/caspase-11/NALP1 and XIAP (Fig. 3) and immunohistochemical data, demonstrating colocalization of these proteins in neurons (Fig. 4).

\section{Spinal cord neurons in culture express NALP1 inflammasome proteins, and valinomycin treatment activates the inflammasome}

We assayed spinal cord neurons grown in culture for expression of inflammasome components. As shown in Figure $5 A$, spinal cord neurons expressed NALP1, ASC, caspase-1, caspase-11, and
XIAP, but the relative proportions of these components in cultured neurons differed from those expressed in spinal cord tissue. To test whether $\mathrm{K}^{+}$efflux is required for NALP1 inflammasome activation, we treated spinal cord neurons with the $\mathrm{K}^{+}$ionophore valinomycin. Valinomycin triggered activation and processing of caspase- 1 (Fig. $5 B$ ) and resulted in a significant increase of IL- $1 \beta(38.72 \pm 3.43 \mathrm{pg} / \mathrm{ml})$ in the culture medium when compared with untreated neurons $(24.24 \pm 0.80 \mathrm{pg} / \mathrm{ml})$. Thus, activation of the NALP1 inflammasome and release of IL- $1 \beta$ in spinal cord neurons is dependent on $\mathrm{K}^{+}$efflux.

\section{ASC neutralization reduces SCI-induced activation and processing of caspase-1, IL-1 $\beta$, IL-18, and XIAP cleavage}

The blood-spinal cord barrier is intact before injury and becomes disrupted by the insult (Schnell et al., 1999a). Because motor neurons have the ability to uptake IgG (Mohammed et al., 2002), we determined whether anti-ASC was taken up by spinal cord neurons in vivo. Anti-ASC-conjugated FITC or FITC alone (control) was administered at $20 \mathrm{~min}$ after SCI, and the injured spinal cord was excised $24 \mathrm{~h}$ later. Cords were sectioned and examined by confocal microscopy (Fig. 6A). Large spinal cord motor neurons stained with FITC-conjugated anti-ASC, whereas FITC administration alone did not label spinal cord neurons. To investigate the mechanism by which the spinal cord incorporates anti-ASC, spinal cord neurons were grown in culture for $7 \mathrm{~d}$. Neurons were treated with cytochalasin D (endocytosis inhibitor) or carbenoxolone (nonspecific pannexin inhibitor) and then incubated with FITC-conjugated anti-ASC, FITC-conjugated actin, or FITC alone (Fig. 6B). Spinal cord neurons incorporated FITC-conjugated anti-ASC, whereas FITC-conjugated actin was excluded from these cells. Moreover, anti-ASC uptake was abolished by pretreatment with carbenoxolone but was not inhibited by cytochalasin D. Thus, it appears that uptake of anti-ASC by spinal cord neurons is sensitive to carbenoxolone treatment.

To dissect the contribution of the NALP1 inflammasome to SCI-induced inflammation, we blocked the activity of the NALP1 inflammasome with antibodies against the inflammasome adaptor protein ASC. Antibody treatment was started $20 \mathrm{~min}$ after trauma. One group of animals received an intravenous $(50 \mu \mathrm{g})$ and an intraperitoneal $(50 \mu \mathrm{g})$ injection of ASC neutralizing antibody. These two routes of antibody delivery were chosen to minimize inflammasome activation systemically and in the CNS. Control groups received saline alone, remained untreated, or received IgG of the same isotype corresponding to anti-ASC.

Spinal cords were removed at $24 \mathrm{~h}$ after treatment, and lysates were prepared and immunoblotted for caspase-1, IL-1 $\beta$, IL-18, and XIAP (Fig. 7). Neutralization of ASC significantly reduced activation and processing of IL- $1 \beta$, IL- 18 , and caspase- 1 and decreased XIAP cleavage. Levels of other proteins comprising the NALP1 complex did not change after antibody neutralization (data not shown). Moreover, spinal cord lysates were tested for caspase-1 protease activity using a caspase-1-specific peptide conjugated to a fluorescent reporter molecule WEHD-AFC (Fig. $7 B)$. Treatment with ASC neutralizing antibody significantly reduced caspase-1 activity (42\%) compared with sham animals, indicating that this treatment strategy significantly decreases activation of one of the key components in inflammasome signaling after trauma to the spinal cord. Thus, ASC neutralization interferes with inflammasome signaling pathways of caspase-1 activation and processing of inflammatory cytokines induced by SCI. 

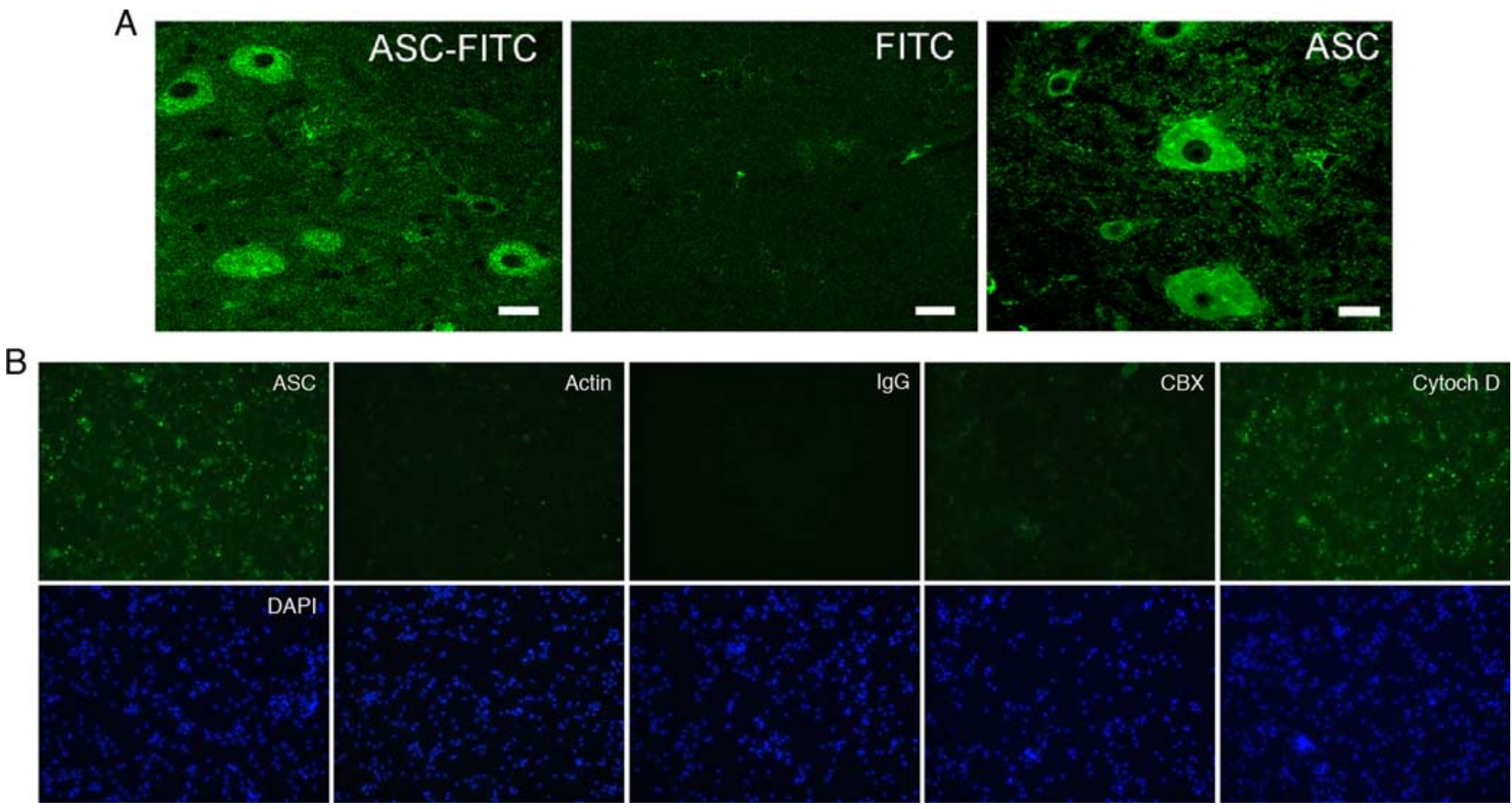

Figure 6. A, Confocal images of spinal cord sections demonstrating that anti-ASC antibody is taken up by spinal cord neurons. Anti-ASC was conjugated to FITC using the EZ-Label FITC Protein Labeling kit (Pierce) according to the instructions of the manufacturer. Rats were subjected to moderate cervical SCl. At 20 min after SCl, $50 \mu \mathrm{g}$ of anti-ASC-FITC was injected intraperitoneally and intravenously. Control injured rats received FITC alone. At $6 \mathrm{~h}$ after SCl, anti-ASC-FITC labeled cervical motor neurons in the ventral horn, whereas these cells were not labeled by administration of FITC alone. The right panel (ASC) shows spinal cord sections immunostained with anti-ASC followed by appropriate secondary antibody for comparison. Scale bars, $20 \mu \mathrm{m}$. $\boldsymbol{B}$, Incorporation of anti-ASC into spinal cord neurons is sensitive to carbenoxolone. Spinal cord neurons were grown for $7 \mathrm{~d}$ and treated with anti-ASC-FITC (ASC), anti-actin-FITC (actin), and lgG-FITC (IgG). Other cultures were pretreated for $10 \mathrm{~min}$ with $100 \mu \mathrm{m}$ carbenoxolone and anti-ASC (CBX) or $30 \mu \mathrm{m}$ cytochalasin D (CytochD) and then incubated with anti-ASC for $1 \mathrm{~h}$. FITC-conjugated anti-ASC was taken up by spinal cord neurons, whereas FITC-conjugated actin and IgG were excluded from these cells. Incorporation of anti-ASC-FITC was blocked by carbenoxolone, whereas cytochalasin D had little effect. The bottom row shows DAPI-labeled nuclei corresponding to cells in top row.

\section{ASC neutralization decreases spinal cord lesion volume}

To determine whether inflammasome signaling was causally linked to tissue damage during SCI in vivo, we blocked the activity of ASC with neutralizing antibodies and measured the lesion volumes at $3 \mathrm{~d}$ after injury. Rats were subjected to cervical SCI and then treated with anti-ASC antibody. Other group of rats were left untreated (no antibody) or treated with IgG and served as controls. Figure $8 \mathrm{~A}$ shows representative spinal cord sections of the lesion epicenter and areas rostral and caudal to the impact site at $3 \mathrm{~d}$ after trauma. Spinal cords from animals treated with anti-ASC demonstrated smaller areas containing shrunken eosinophilic neurons in gray matter (Fig. $8 B$, arrowheads) and reduced white matter degeneration (Fig. $8 B$, arrows). Importantly, administration of anti-ASC antibody significantly reduced (43\%) the lesion volume as determined by diminished white matter degeneration and preservation of motor neuron morphology (Fig. $8 B$ ).

\section{ASC neutralization improves functional outcomes after SCI}

To investigate the long-term consequences of neutralization of ASC, we conducted tests that reflected the integrity of dorsal spinal motor tracts (corticospinal or rubrospinal). The grip strength test directly measures the force with which the rat grasps objects and reflects the loss of motor neurons at C5-C6 of the spinal cord. Rats were treated with neutralizing antibodies to ASC, with IgG, or were left untreated as controls. Only rats exhibiting a significant improvement in grip strength were those treated with neutralizing antibodies (Fig. 9A). Deficits in descending motor control were examined by assessing the ability of the rat to remove a sticker placed on their nose bridge (Diener and Bregman, 1998). Again, only rats treated with anti-ASC antibody showed a significant recovery of voluntary movement compared with control rats (Fig. 9B). We conducted footprint analysis to examine motor coordination and evaluate foot placement and stance during locomotion. Animals treated with neutralizing antibodies had significant improvements in base of support (Fig. 9C) and foot rotation (Fig. 9E), but there was no significant improvement in stride length (Fig. 9D). Thus, ASC neutralization enhances voluntary movement and improves posture and balance after cervical SCI.

\section{Discussion}

In this study, we have shown for first time the eminent role of the NALP1 inflammasome system in determining outcomes after cervical SCI in the rat. Our data show that SCI initiates the activation of a molecular platform that results in processing of caspase- 1 and upregulation of caspase-11 and the adaptor protein ASC, leading to maturation of IL- $1 \beta$ and IL-18. The molecular platform termed the NALP1 inflammasome is present in motor neurons of the spinal cord and activates caspase- 1 after injury. The neuronal NALP1 inflammasome is a multiprotein complex consisting of inflammatory caspase-1, caspase-11, NALP1, the adaptor protein ASC, and the inhibitor of apoptosis protein XIAP. Neutralization of ASC leads to significant tissue sparing and behavioral improvement, suggesting a protective response by this treatment. Thus, the NALP1 inflammasome constitutes an important arm of the innate CNS inflammatory response after SCI. 


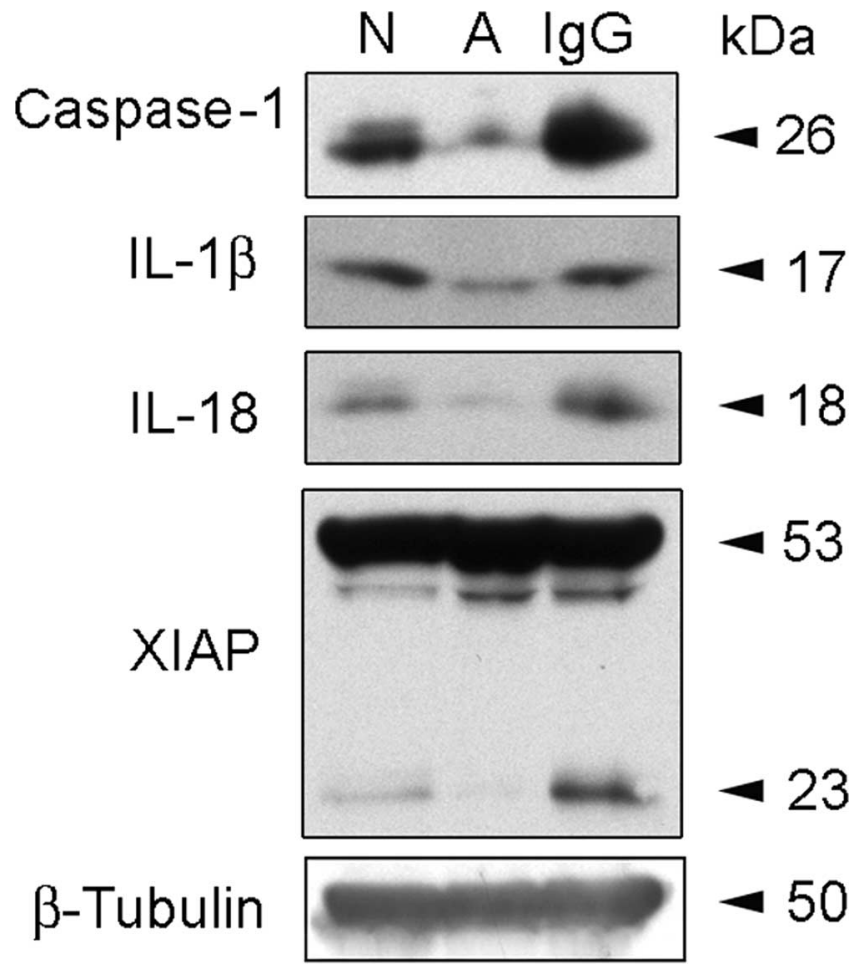

Figure 7. ASC neutralization decreases SCl-induced activation and processing of caspase-1, IL-1 $\beta$, IL-18, and XIAP cleavage. Representative immunoblots of injured spinal cords from animals subjected to $\mathrm{SCl}$ and treated intraperitoneally and intravenously with antibodies to ASC (A), lgG controls (IgG), or were left untreated ( $\mathrm{N}$ ) at 20 min after injury. Animals were killed $24 \mathrm{~h}$ after treatment. Treatment resulted in inhibition of inflammasome activation as detected by a decrease in the processing of procaspase-1, cleavage of XIAP, and a reduction in the levels of cleaved IL-1 $\beta$ and IL-18.

IL- $1 \beta$ and IL-18 have potent proinflammatory actions that promote T-helper 1 (TH1)-associated responses (Benveniste, 1992; Bhat et al., 1996; Burns et al., 2003; Dinarello, 2005, 2006; Schmitz et al., 2005). During cleavage of their proforms by caspase-1, these cytokines become active and are secreted. Thus, caspase- 1 activity is critical for the inflammatory response. However, more than one proinflammatory caspase may be implicated in the generation of active IL-1 $\beta$ and IL-18 (Wang et al., 1998). Here we report that caspase- 1 and caspase- 11 are recruited to the rat NALP1 complex after SCI. ASC immunoprecipitates from sham spinal cords contained the full-length caspase-1 and caspase-11, whereas immunoprecipitates from injured cords contained full-length and cleaved fragments of caspase-1. A physical interaction between murine caspase- 1 and caspase- 11 has been demonstrated previously, and genetic evidence supports a crucial role of both caspases in processing of IL- $1 \beta$ and IL-18 (Wang et al., 1998). Thus, caspase-1 activation and recruitment of caspase- 11 to the inflammasome complex may be involved in the generation of active IL- $1 \beta$ and IL-18 in the rat spinal cord. Human ASC and caspase-1 associate with each other by homodimeric interactions via their respective CARD, whereas ASC is thought to interact with NALP1 via the PYRIN domain. In mice, this domain is expressed in a functional NALP1b allele (Boyden and Dietrich, 2006). Therefore, it is possible that NALP1 in the rat spinal cord-inflammasome complex may be encoded by a NALP1 allele similar to the NALP1b gene in mice. However, additional rat genomic sequencing is required to validate this possibility.

Assembly of the inflammasome depends on NOD-like recep- tor family members such as NALPs. Our data show that the inflammasome in neurons is a protein complex containing NALP1 as a scaffolding protein that activates caspase- 1 to promote IL- $1 \beta$ maturation. Although the total levels of NALP1 in lysates did not change significantly after SCI (Fig. 2), the proportion of NALP1 that forms the inflammasome increases (Fig. 3). Moreover, reconstitution studies using purified recombinant proteins show that caspase- 1 activation by NALP1 does not require but is enhanced by the adaptor protein ASC (Faustin et al., 2007). Thus, ASC present in the NALP1 inflammasome complex in neurons may serve to amplify the inflammatory response induced by SCI. The observed decrease in ASC expression at $3 \mathrm{~h}$ after injury (Fig. 2C) may represent a CNS response to inhibit inflammation during the acute injury phase. This interpretation is consistent with recent observations in our laboratory (our unpublished data), demonstrating that decreased ASC expression correlates with increased expression of the immunosuppressive cytokine IL-33 at $3 \mathrm{~h}$ after SCI.

The inflammasome in normal tissues is speculated to be in an inactive state by binding to a putative inhibitor (Dinarello, 2005), but the nature of this inhibitor has not been identified. Recently, it has been shown that the antiapoptotic proteins Bcl-2 and $\mathrm{Bcl}-\mathrm{X}_{\mathrm{L}}$ bind and suppress NALP1, reducing activation and production of IL-1 $\beta$ in macrophages (Bruey et al., 2007). Our data demonstrate that full-length XIAP is associated with the NALP1 inflammasome in rat neurons. Other inhibitors of apoptosis proteins, namely cellular inhibitor-of-apoptosis protein 1 (cIAP1), cIAP2, and NAIP, did not interact with this inflammasome complex (data not shown). Moreover, SCI-induced activation of the inflammasome was found to be associated with cleavage of XIAP into fragments. Cleavage of XIAP produces an N-terminal BIR1-2 fragment with reduced ability to inhibit caspases (Katz et al., 2001; Keane et al., 2001; Lotocki and Keane, 2002). Therefore, SCI-induced XIAP cleavage may reduce the threshold for activation of caspase-1, leading to processing and secretion of IL- $1 \beta$ and IL-18. We suggest that XIAP in the NALP1 inflammasome complex may serve to inhibit caspase- 1 activity, preventing the activation and processing of IL- $1 \beta$ and IL-18. Additional studies with XIAP-deficient animals are needed to determine the consequences of XIAP cleavage in SCI-induced inflammasome signaling to test this hypothesis.

Three types of inflammasomes in humans have been proposed based on biochemical analysis of three-Apaf-like proteins, NALP1, NALP2/3, and Ipaf (Tschopp et al., 2003; Agostini et al., 2004; Dinarello, 2004b). Diverse stimuli and ligands have been shown to activate inflammasomes. Bacterial RNA (Laye et al., 1996; Martinon et al., 2004; Franchi et al., 2006; Miao et al., 2006; Ozoren et al., 2006), viral RNA (Kanneganti et al., 2006), lipopolysaccharide (Kanai et al., 2000; Mariathasan et al., 2004, 2006), CpG-DNA and flagellin (Franchi et al., 2006; Miao et al., 2006), uric acid crystals (Martinon et al., 2006), and a decrease in intracellular $\mathrm{K}^{+}$levels (Petrilli et al., 2007) are known to activate inflammasome signaling, resulting in activation of caspase-1. These studies demonstrate that multiple types of signals appear to converge at caspase- 1 activation through multiple inflammasomes. Our studies show that moderate SCI induces activation of caspase-1, increases levels of caspase-11 and ASC, and promotes association of NALP1 inflammasome proteins in neurons. The precise SCI-induced stimulus that activates the NALP1 inflammasome remains unclear, but our studies show that decreased levels of intracellular $\mathrm{K}^{+}$in neurons results in caspase- 1 activation and release of IL- $1 \beta$ in cultured spinal cord neurons. This finding is in agreement with the observation that the NALP1 and 
NALP3 inflammasomes are triggered by low intracellular $\mathrm{K}^{+}$concentrations (Petrilli et al., 2007).

IL- $1 \beta$ is synthesized by neuronal and glial cells (Lechan et al., 1990) and is released in response to injury, insult, and stress (Benveniste, 1992; Bhat et al., 1996; Bartholdi and Schwab, 1997; Dinarello, 2004a, 2006). We found that spinal cord neurons, which are generally not associated with immune functions, express NALP1 inflammasome proteins. The expression and cellular localization of these proteins changed acutely after cervical SCI and are in agreement with recent findings that show NALP1 expression in neurons of the human brain (Kummer et al., 2007). Our results suggest that NALP1 inflammasome activity is fundamental for the processing of IL- $1 \beta$ and IL-18 and for the innate inflammatory response in neurons. However, ASC, caspase-1, and caspase-11 are also present in astrocytes, oligodendrocytes, and microglial cells. Therefore, characterization of the composition and subcellular localization of inflammasomes in glia may provide a clearer insight into the mechanisms leading to cytokine secretion and cell death caused by caspase- 1 after SCI. Because neurons do not act as antigen presenting cells and have limited immune functions, it is possible that the NALP1 inflammasome provides neurons with a form of innate immunity in a capacity to synthesize and release IL-1 $\beta$. Thus, traumainduced NALP1 inflammasome activation in neurons could lead to reactive gliosis in neighboring cells mediated by IL- $1 \beta$ released from neurons. In support of this idea are reports that neurons communicate with microglia via cytokine release, resulting in a TH1 response (Fields and StevensGraham, 2002; Sonetti and Peruzzi, 2004).

Currently, strategies aimed at treating spinal cord lesions focus on neuroprotection, enhanced regeneration, or treatment of demyelination. Our study shows that neutralization of ASC significantly reduces caspase- 1 activation, XIAP cleavage, and processing of IL- $1 \beta$ and IL- 18 , resulting in significant improvement in tissue sparing and functional recovery. Moreover, anti-ASC was taken up by spinal cord neurons. Fabian and Petroff (1987) have shown that CNS motor neurons take up plasma IgG at the motor axon terminal in the periphery and retrogradely transport IgG to the cell body. IgG from rats inoculated with brain synaptosomes is taken up by motor neurons with a greater extent than nonspecific IgG (Fabian, 1987). Moreover, IgG prepared from amyotrophic lateral sclerosis patient serum is taken up into motor neurons more readily than disease control IgG (Mohammed et al., 2002). Collectively, these data show that motor neurons have the ability to uptake IgG. Our studies show that motor neurons in the ventral horn of the injured spinal cord take up anti-ASC, possibly
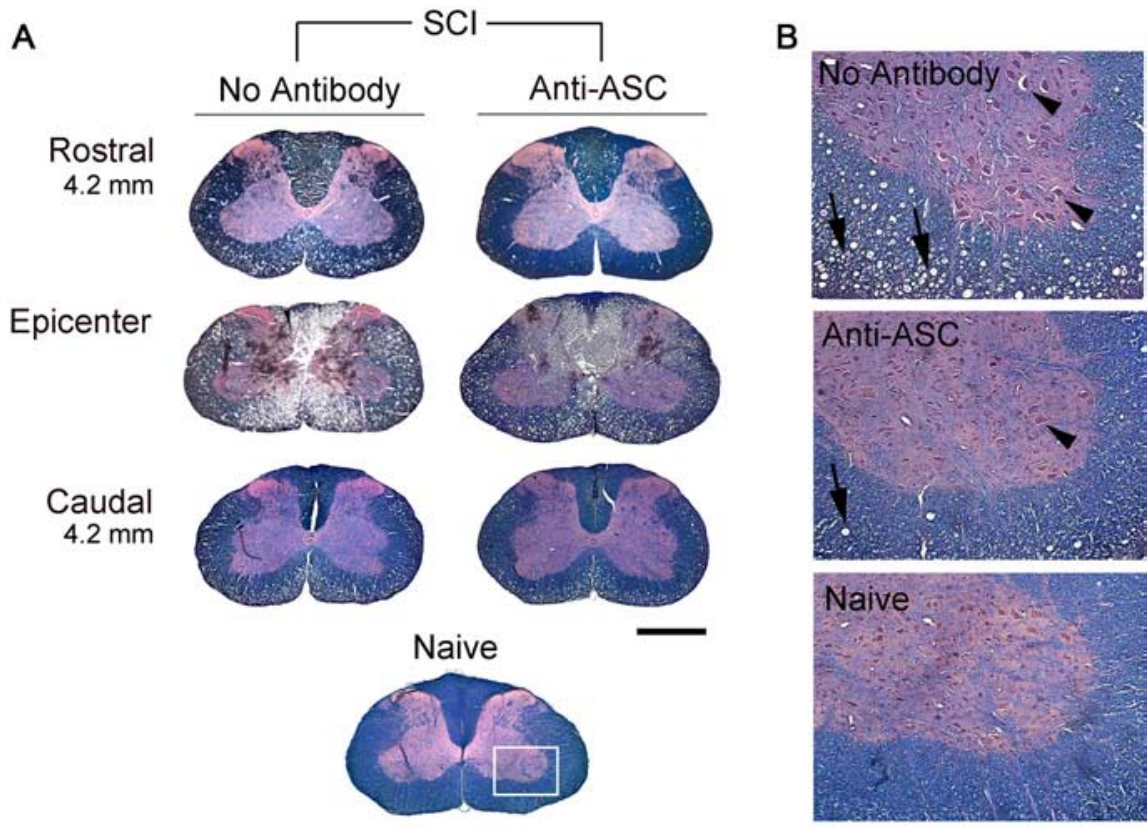

Figure 8. ASC neutralization improves histopathological outcome and decreases spinal cord lesion volume. $\boldsymbol{A}$, Representative cross sections of spinal cords of antibody-treated (Anti-ASC) and nontreated (No Antibody) animals at $3 \mathrm{~d}$ after SCl. Hematoxylineosin and luxol fast blue stained sections represent the injury epicenter and sites $4.2 \mathrm{~mm}$ rostral and caudal to the epicenter. Administration of anti-ASC significantly reduced the lesion volume at $3 \mathrm{~d}$ after injury. Areas of degeneration evaluated for volumetric analysis of lesion volume were determined by diminished white matter degeneration and preservation of motor neuron morphology. Significance was determined by comparing average lesion volume of antibody-treated animals to control groups using Student's $t$ test ( $n=5$ per group). There were no differences between nontreated animals (no antibody) and IgG-treated controls. $\boldsymbol{B}$, Spinal cords from animals treated with anti-ASC demonstrated smaller areas of shrunken neurons in gray matter (arrowheads) and reduced white matter degeneration (arrows). Scale bar, $50 \mu \mathrm{m}$.
A
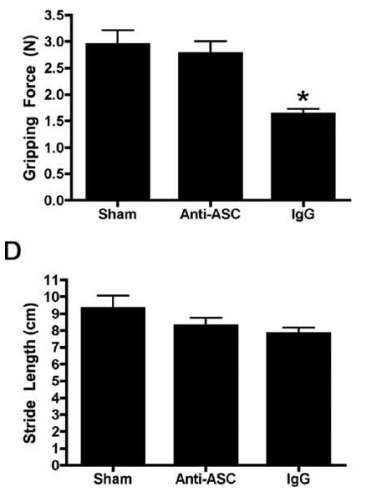

B

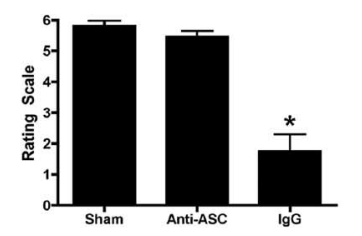

$\mathrm{E}$

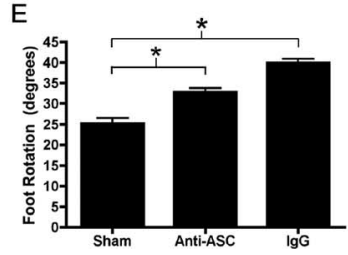

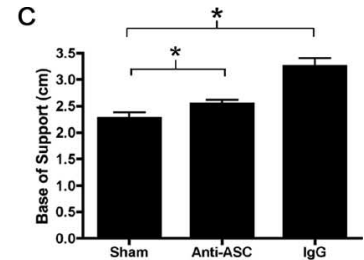

C Sham Anti-ASC $\lg G$
Figure 9. ASC neutralization improves functional outcomes after $\mathrm{SCl}$. $\boldsymbol{A}-\boldsymbol{E}$, After $\mathrm{SCl}$, a person blinded to the treatment protocols assessed behavior with the following tests: gripping force $(\boldsymbol{A})$, sticker removal $(\boldsymbol{B})$, footprint analysis/base of support $(\boldsymbol{C})$, stride length $(\boldsymbol{D})$, and foot rotation $(\boldsymbol{E})$. Data are presented as the mean \pm SD. ${ }^{*} p<0.05$ compared with sham.

through a mechanism involving the hemichannel pannexin-1. Because the pannexin-1 channel has a cutoff limit for the penetration of molecules of 1500-2000 Da (Wang et al., 2007), it is unlikely that it provides a direct pathway for the permeability of these antibody molecules. However, recently it has been shown that pannexin-1 provides a mechanism by which bacteria and bacterial products directly enter the cell, resulting in activation of caspase-1 (Kanneganti et al., 2007; Wang et al., 2007). Thus, pannexin-1 appears to be involved in the activation of caspase- 1 .

The improvement in functional recovery of antibody-treated animals was paralleled by increased sparing of white and gray matter. The forelimb grip-strength, sticker removal, and foot- 
print analysis tests assess kinetic and kinematic measures controlled by descending corticospinal tracts. Thus, the improved functional outcomes exhibited by rats that received neutralizing antibody was likely the result of spared tissue in the main dorsal tract, the dorsolateral spinal cord, and the ventral spinal cord (Brosamle and Schwab, 1997; Steward et al., 2004). We propose that anti-ASC inhibits the enhancement of inflammasome signaling and the release of matured cytokines, thus inhibiting cell death. However, we cannot rule out the possibility that ASC neutralization promotes axonal regeneration, leading to the observed improvement in behavior. Inflammasome inhibition might offer a new therapy for human spinal cord trauma and CNS inflammatory diseases.

\section{References}

Agostini L, Martinon F, Burns K, McDermott MF, Hawkins PN, Tschopp J (2004) NALP3 forms an IL-1beta-processing inflammasome with increased activity in Muckle-Wells autoinflammatory disorder. Immunity 20:319-325.

Bareyre FM, Schwab ME (2003) Inflammation, degeneration and regeneration in the injured spinal cord: insights from DNA microarrays. Trends Neurosci 26:555-563.

Bartholdi D, Schwab ME (1997) Expression of pro-inflammatory cytokine and chemokine mRNA upon experimental spinal cord injury in mouse: an in situ hybridization study. Eur J Neurosci 9:1422-1438.

Benveniste EN (1992) Inflammatory cytokines within the central nervous system: sources, function, and mechanism of action. Am J Physiol 263:C1-C16.

Bethea JR (2000) Spinal cord injury-induced inflammation: a dual-edged sword. Prog Brain Res 128:33-42.

Bethea JR, Dietrich WD (2002) Targeting the host inflammatory response in traumatic spinal cord injury. Curr Opin Neurol 15:355-360.

Bhat RV, DiRocco R, Marcy VR, Flood DG, Zhu Y, Dobrzanski P, Siman R, Scott R, Contreras PC, Miller M (1996) Increased expression of IL-1beta converting enzyme in hippocampus after ischemia: selective localization in microglia. J Neurosci 16:4146-4154.

Boyden ED, Dietrich WF (2006) Nalp1b controls mouse macrophage susceptibility to anthrax lethal toxin. Nat Genet 38:240-244.

Brosamle C, Schwab ME (1997) Cells of origin, course, and termination patterns of the ventral, uncrossed component of the mature rat corticospinal tract. J Comp Neurol 386:293-303.

Bruey JM, Bruey-Sedano N, Luciano F, Zhai D, Balpai R, Xu C, Kress CL, Bailly-Maitre B, Li X, Osterman A, Matsuzawa S, Terskikh AV, Faustin B, Reed JC (2007) Bcl-2 and Bcl-XL regulate proinflammatory caspase-1 activation by interaction with NALP1. Cell 129:45-56.

Burns K, Martinon F, Tschopp J (2003) New insights into the mechanism of IL-1beta maturation. Curr Opin Immunol 15:26-30.

Carmel JB, Galante A, Soteropoulos P, Tolias P, Recce M, Young W, Hart RP (2001) Gene expression profiling of acute spinal cord injury reveals spreading inflammatory signals and neuron loss. Physiol Genomics 7:201-213.

de Medinaceli L, Freed WJ, Wyatt RJ (1982) An index of the functional condition of rat sciatic nerve based on measurements made from walking tracks. Exp Neurol 77:634-643.

Diener PS, Bregman BS (1998) Fetal spinal cord transplants support the development of target reaching and coordinated postural adjustments after neonatal cervical spinal cord injury. J Neurosci 18:763-778.

Dinarello CA (2004a) Interleukin-18 and the treatment of rheumatoid arthritis. Rheum Dis Clin North Am 30:417-434, ix.

Dinarello CA (2004b) Unraveling the NALP-3/IL-1beta inflammasome: a big lesson from a small mutation. Immunity 20:243-244.

Dinarello CA (2005) Blocking IL-1 in systemic inflammation. J Exp Med 201:1355-1359.

Dinarello CA (2006) Interleukin 1 and interleukin 18 as mediators of inflammation and the aging process. Am J Clin Nutr 83:447S-455S.

Dusart I, Schwab ME (1994) Secondary cell death and the inflammatory reaction after dorsal hemisection of the rat spinal cord. Eur J Neurosci 6:712-724.

Fabian RH, Petroff G (1987) Intraneuronal IgG in the central nervous system: uptake by retrograde axonal transport. Neurology 37:1780-1784.
Faustin B, Lartigue L, Bruey JM, Luciano F, Sergienko E, Bailly-Maitre B, Volkmann N, Hanein D, Rouiller I, Reed JC (2007) Reconstituted NALP1 inflammasome reveals two-step mechanism of caspase-1 activation. Mol Cell 25:713-724.

Fields RD, Stevens-Graham B (2002) New insights into neuron-glia communication. Science 298:556-562.

Franchi L, Am A, Body-Malapel M, Kanneganti TD, Ozoren N, Jagirdar R, Inohara N, Vandenabeele P, Bertin J, Coyle A, Grant EP, Nunez G (2006) Cytosolic flagellin requires Ipaf for activation of caspase-1 and interleukin 1beta in salmonella-infected macrophages. Nat Immunol 7:576-582.

Kanai T, Watanabe M, Okazawa A, Nakamaru K, Okamoto M, Naganuma M, Ishii H, Ikeda M, Kurimoto M, Hibi T (2000) Interleukin 18 is a potent proliferative factor for intestinal mucosal lymphocytes in Crohn's disease. Gastroenterology 119:1514-1523.

Kanneganti TD, Body-Malapel M, Am A, Park JH, Whitfield J, Franchi L, Taraporewala ZF, Miller D, Patton JT, Inohara N, Nunez G (2006) Critical role for Cryopyrin/Nalp3 in activation of caspase-1 in response to viral infection and double-stranded RNA. J Biol Chem 281:36560-36568.

Kanneganti TD, Lamkanfi M, Kim YG, Chen G, Park JH, Franchi L, Vandenabeele P, Nunez G (2007) Pannexin-1-mediated recognition of bacterial molecules activates the cryopyrin inflammasome independent of Tolllike receptor signaling. Immunity 26:433-443.

Katz LM, Lotocki G, Wang Y, Kraydieh S, Dietrich WD, Keane RW (2001) Regulation of caspases and XIAP in the brain after asphyxial cardiac arrest in rats. NeuroReport 12:3751-3754.

Kawamoto JC, Barrett JN (1986) Cryopreservation of primary neurons for tissue culture. Brain Res 384:84-93.

Keane RW, Tallent MW, Podack ER (1992) Resistance and susceptibility of neural cells to lysis by cytotoxic lymphocytes and by cytolytic granules. Transplantation 54:520-526.

Keane RW, Srinivasan A, Foster LM, Testa MP, Ord T, Nonner D, Wang HG, Reed JC, Bredesen DE, Kayalar C (1997) Activation of CPP32 during apoptosis of neurons and astrocytes. J Neurosci Res 48:168-180.

Keane RW, Kraydieh S, Lotocki G, Bethea JR, Krajewski S, Reed JC, Dietrich WD (2001) Apoptotic and anti-apoptotic mechanisms following spinal cord injury. J Neuropathol Exp Neurol 60:422-429.

Kuida K, Lippke JA, Ku G, Harding MW, Livingston DJ, Su MS, Flavell RA (1995) Altered cytokine export and apoptosis in mice deficient in interleukin-1 beta converting enzyme. Science 267:2000-2003.

Kummer JA, Broekhuizen R, Everett H, Agostini L, Kuijk L, Martinon F, van Bruggen R, Tschopp J (2007) Inflammasome components NALP 1 and 3 show distinct but separate expression profiles in human tissues suggesting a site-specific role in the inflammatory response. J Histochem Cytochem 55:443-452.

Laye S, Goujon E, Combe C, VanHoy R, Kelley KW, Parnet P, Dantzer R (1996) Effects of lipopolysaccharide and glucocorticoids on expression of interleukin-1 beta converting enzyme in the pituitary and brain of mice. J Neuroimmunol 68:61-66.

Lechan RM, Toni R, Clark BD, Cannon JG, Shaw AR, Dinarello CA, Reichlin S (1990) Immunoreactive interleukin-1 beta localization in the rat forebrain. Brain Res 514:135-140.

Lotocki G, Keane RW (2002) Inhibitors of apoptosis proteins in injury and disease. IUBMB Life 54:231-240.

Mariathasan S, Newton K, Monack DM, Vucic D, French DM, Lee WP, Roose-Girma M, Erickson S, Dixit VM (2004) Differential activation of the inflammasome by caspase-1 adaptors ASC and Ipaf. Nature 430:213-218.

Mariathasan S, Weiss DS, Newton K, McBride J, O’Rourke K, Roose-Girma M, Lee WP, Weinrauch Y, Monack DM, Dixit VM (2006) Cryopyrin activates the inflammasome in response to toxins and ATP. Nature 440:228-232.

Martinon F, Tschopp J (2004) Inflammatory caspases: linking an intracellular innate immune system to autoinflammatory diseases. Cell 117:561-574.

Martinon F, Tschopp J (2007) Inflammatory caspases and inflammasomes: master switches of inflammation. Cell Death Differ 14:10-22.

Martinon F, Burns K, Tschopp J (2002) The inflammasome: a molecular platform triggering activation of inflammatory caspases and processing of proIL-beta. Mol Cell 10:417-426.

Martinon F, Agostini L, Meylan E, Tschopp J (2004) Identification of bacterial muramyl dipeptide as activator of the NALP3/cryopyrin inflammasome. Curr Biol 14:1929-1934. 
Martinon F, Petrilli V, Mayor A, Tardivel A, Tschopp J (2006) Goutassociated uric acid crystals activate the NALP3 inflammasome. Nature 440:237-241.

Miao EA, Alpuche-Aranda CM, Dors M, Clark AE, Bader MW, Miller SI, Aderem A (2006) Cytoplasmic flagellin activates caspase-1 and secretion of interleukin 1beta via Ipaf. Nat Immunol 7:569-575.

Mohamed HA, Mosier DR, Zou LL, Siklós L, Alexianu ME, Engelhardt JI, Beers DR, Le WD, Appel SH (2002) Immunoglobulin Fc gamma receptor promotes immunoglobulin uptake, immunoglobulin-mediated calcium increase, and neurotransmitter release in motor neurons. J Neurosci Res 69:110-116.

Norenberg MD, Smith J, Marcillo A (2004) The pathology of human spinal cord injury: defining the problems. J Neurotrauma 21:429-440.

Ogura Y, Sutterwala FS, Flavell RA (2006) The inflammasome: first line of the immune response to cell stress. Cell 126:659-662.

Ozoren N, Masumoto J, Franchi L, Kanneganti TD, Body-Malapel M, Erturk I, Jagirdar R, Zhu L, Inohara N, Bertin J, Coyle A, Grant EP, Nunez G (2006) Distinct roles of TLR2 and the adaptor ASC in IL-1beta/IL-18 secretion in response to Listeria monocytogenes. J Immunol 176:4337-4342.

Pearse DD, Pereira FC, Stolyarova A, Barakat DJ, Bunge MB (2004) Inhibition of tumour necrosis factor-alpha by antisense targeting produces immunophenotypical and morphological changes in injury-activated microglia and macrophages. Eur J Neurosci 20:3387-3396.

Pearse DD, Lo Jr TP, Cho KS, Lynch MP, Garg MS, Marcillo AE, Sanchez AR, Cruz Y, Dietrich WD (2005) Histopathological and behavioral characterization of a novel cervical spinal cord displacement contusion injury in the rat. J Neurotrauma 22:680-702.

Petrilli V, Papin S, Dostert C, Mayor A, Martinon F, Tschopp J (2007) Activation of the NALP3 inflammasome is triggered by low intracellular potassium concentration. Cell Death Differ 14:1583-1589.

Popovich PG, Wei P, Stokes BT (1997) Cellular inflammatory response after spinal cord injury in Sprague-Dawley and Lewis rats. J Comp Neurol 377:443-464.
Popovich PG, Stuckman S, Gienapp IE, Whitacre CC (2001) Alterations in immune cell phenotype and function after experimental spinal cord injury. J Neurotrauma 18:957-966.

Popovich PG, Guan Z, McGaughy V, Fisher L, Hickey WF, Basso DM (2002) The neuropathological and behavioral consequences of intraspinal microglial/macrophage activation. J Neuropathol Exp Neurol 61:623-633.

Schmitz J, Owyang A, Oldham E, Song Y, Murphy E, McClanahan TK, Zurawski G, Moshrefi M, Qin J, Li X, Gorman DM, Bazan JF, Kastelein RA (2005) IL-33, an interleukin-1-like cytokine that signals via the IL-1 receptor-related protein ST2 and induces T helper type 2-associated cytokines. Immunity 23:479-490.

Schnell L, Fearn S, Klassen H, Schwab ME, Perry VH (1999a) Acute inflammatory responses to mechanical lesions in the CNS: differences between brain and spinal cord. Eur J Neurosci 11:3648-3658.

Schnell L, Fearn S, Schwab ME, Perry VH, Anthony DC (1999b) Cytokineinduced acute inflammation in the brain and spinal cord. J Neuropathol Exp Neurol 58:245-254.

Sonetti D, Peruzzi E (2004) Neuron-microglia communication in the CNS of the freshwater snail Planorbarius corneus. Acta Biol Hung 55:273-285.

Steward O, Zheng B, Ho C, Anderson K, Tessier-Lavigne M (2004) The dorsolateral corticospinal tract in mice: an alternative route for corticospinal input to caudal segments following dorsal column lesions. J Comp Neurol 472:463-477.

Tedeschi B, Barrett JN, Keane RW (1986) Astrocytes produce interferon that enhances the expression of $\mathrm{H}-2$ antigens on a subpopulation of brain cells. J Cell Biol 102:2244-2253.

Tschopp J, Martinon F, Burns K (2003) NALPs: a novel protein family involved in inflammation. Nat Rev Mol Cell Biol 4:95-104.

Wang J, Ma M, Locovei S, Keane RW, Dahl G (2007) Modulation of membrane channel currents by gap junction protein mimetic peptides: size matters. Am J Physiol Cell Physiol 293:C1112-C1119.

Wang S, Miura M, Jung YK, Zhu H, Li E, Yuan J (1998) Murine caspase-11, an ICE-interacting protease, is essential for the activation of ICE. Cell 92:501-509. 